\title{
O CÓDIGO DE DEFESA DO CONSUMIDOR E A LEI DE PLANOS DE SAÚDE: APLICAÇÃO COGENTE E COMPLEMENTAR NOS CONTRATOS COLETIVOS DE ASSISTÊNCIA À SAÚDE
}

\author{
CODE OF CONSUMER DEFENSE AND FORM OF APPLIED HEALTH \\ INSURANCE LAW AND SUPPLEMENTARY COGENT IN COLLECTIVE \\ AGREEMENT TO HEALTH ASSISTANCE.
}

\author{
${ }^{1}$ Jussara Suzi Assis Borges Nasser Ferreira \\ ${ }^{2}$ Rodolfo Souza Paulino
}

\begin{abstract}
RESUMO
Os contratos de assistência à saúde, na modalidade coletiva, formam a grande massa de contratação entre usuários e operadoras. Este tipo de contratação necessita de maiores adequações, principalmente no que se refere à forma de aplicação das leis cogentes e complementares que protegem a grande massa de consumidores, sendo que vários contratos permanecem carentes em relação à adequada interpretação dos dispositivos legais, de forma pertinente à tutela dos interesses dos consumidores.
\end{abstract}

Palavras-chave: Contrato, Consumidor, Norma, Cogente, Hermenêutica

\begin{abstract}
Health-care contracts, the collective mode, form the bulk of contracting between users and operators. This type of contract requires major adjustments, especially in regard to the form of application of cogent and complementary laws that protect the great mass of consumers, and several contracts remain disadvantaged in relation to the proper interpretation of legal provisions in an appropriate manner to protection of consumers' interests.
\end{abstract}

Keywords: Contract agreement, Consumer, Standard, Cogent, Hermeneutics

\footnotetext{
${ }^{1}$ Doutora em Direito pela Pontifícia Universidade Católica de São Paulo - PUC, São Paulo (Brasil). Professora de Direito Universidade Paranaense - UNIPAR, Paraná (Brasil). E-mail: jussara@bflaw.adv.br

${ }^{2}$ Mestrando em Direito pela Universidade de Marília - UNIMAR, São Paulo (Brasil). Professor de Direito Civil pela Faculdade de Educação, Ciências e Artes Dom Bosco de Monte Aprazível - FAECA, São Paulo (Brasil). E-mail: paulinoadvocacia@hotmail.com
} 


\section{INTRODUÇÃO}

A saúde pública brasileira enfrenta, em termos de atendimento à população, um de seus piores períodos.

Diante deste cenário caótico, torna-se cada vez mais crescente o número de pessoas que buscam assistência médica privada. Entretanto, este número é imensamente superior quando se trata de contratos coletivos por adesão ou empresariais.

A Agência Nacional de Saúde Suplementar, que tem entre outras funções a de fiscalizar e estabelecer regras para este imenso público, deixa a desejar e, muitas vezes, torna-se omissa em situações que não podem, ou pelo menos não poderiam, ficar sem atenção.

O entendimento humanístico internacional e nacional vem interpretando que o direito à manutenção da saúde está ligado diretamente ao direito à vida e, portanto, protegido pelas legislações contemporâneas voltadas à defesa dos direitos humanos, devendo ser respeitado como tal.

Serão analisados pontos relevantes à pesquisa, por exigirem considerações mais adequadas, a fim de permitir o oferecimento de análises importantes à contribuição útil em relação a busca da resolução dos problemas atuais no que se refere à interpretação e aplicação das normas sob estudo no que destinadas à proteção do consumidor contratante e plano de saúde coletivo. Consoante a tutela constitucional da defesa do consumidor em relação ao direito fundamental à saúde demanda investigar os fundamentos e forma a respeito de como Estado brasileiro regulamentou as normas que tratam da questão de saúde suplementar e como está operacionalizada a respectiva aplicabilidade, se coerente ou não em relação ao consumidor, titular do direito fundamental à saúde.

Neste ponto, reside o objeto da investigação, demarcado pelas digressões observadas e contidas dentre os textos normativos reguladores da tutela ao direito fundamental à saúde do consumidor e respectivas interpretações e juízo decisório em relação ao caso concreto.

A problematização nesta quadra, reveste-se da complexidade própria de circunstâncias como a do estudo, ao envolver tutela jurídica de direito fundamental em dobro por tratar da saúde do consumidor, sendo questionado o concreto juízo decisório quando em desfavor do titular, cabendo remarcar os fins de decisão, que ao invocar preceito normativo pertinente à matéria, reveste-se de fundamentos reveladores de 
inadequação ao eixo principal da devida proteção, obstaculizando a efetivação da proteção do consumidor e sua saúde, usuário de plano de saúde coletivo.

A centralidade metodológica da pesquisa reside na base dedutiva e sistêmica na qual desvela análises críticas centradas na busca da revelação do sentido dos eixos normativos sob comento e a busca dos fins práticos almejados. O capeamento da metódica constitucional, por indispensável, permanece atrelado à interpretação dos direitos fundamentais invocados em outra defesa específica, atrelada à defesa da parte hipossuficiente nos pactos de saúde coletivos.

\section{OS DIREITOS FUNDAMENTAIS DA SAÚDE E DO CONSUMIDOR}

O direito à saúde vinculado, por indispensável, à vida das pessoas, tratado no plano internacional dentre os direitos humanos, recebe proteção constitucional nos ordenamentos jurídicos contemporâneos elencados dentre os direitos fundamentais, sendo o Estado o primeiro responsável pela manutenção e recuperação da saúde dos cidadãos. Sendo o direito do consumidor, igualmente fundamental por disposição constitucional, qualquer violação nessas circunstâncias implicam em violação de duplo grau a tais direitos, reunidos em um mesmo pacto.

A atribuição ao Estado brasileiro do dever de garantir a saúde e sua manutenção decorre da influência emanada da Declaração Universal dos Direitos Humanos quando, no Art. 25.1, enfatiza: "Todo ser humano tem direito a um padrão de vida capaz de assegurar a si e a sua família saúde e bem estar, inclusive alimentação, vestuário, habitação, cuidados médicos e os serviços sociais indispensáveis”.

No Brasil, a Constituição Federal ${ }^{1}$ de 1.988 assegura a todos o direito à saúde, em vários dispositivos, definindo princípios e regras de competência no que concerne à saúde pública, a atribuir expressamente este dever ao Estado no Art.6 ${ }^{\circ}$, capitulado dentre os direitos sociais e, em seguida, garantindo, por meio da dicção do Art. 196, assegurando "políticas sociais e econômicas que visem à redução do risco de doença e de outros agravos e ao acesso universal e igualitário às ações e serviços para sua promoção, proteção e recuperação". O Art. 170, insere dentre os princípios da Ordem Econômica, a defesa do consumidor.

\footnotetext{
1 BRASIL. Constituição Federal de 1.988. Promulgada em 5 de outubro de 1.988. Disponível em: <http://www.planalto.gov.br/ccivil_03/Constituicao/Constituicao.htm> acessado em 17/03/2016.
} 
O direito à vida e, por conseguinte o direito à saúde, têm elevada importância na hierarquia dos direitos fundamentais, conjugados com a defesa do consumidor, sendo vitais ao indivíduo, à sociedade e ao Estado.

Daniela Batalha Trettel remarca a importância da inserção dos direitos relacionados à saúde no rol dos direitos humanos, ressaltando que o direito à saúde decorre do direito à vida.

Todos os serviços de saúde, mesmo os prestados pela iniciativa privada, envolvem direitos fundamentais, sendo constitucionalmente considerados como de relevância pública. Não se trata, portanto, de um negócio qualquer - ou serviço, na acepção do Código de Defesa do Consumidor -, livre à iniciativa privada, para que o presta de maneira que melhor lhe aprouver - leia-se "de maneira menos custosa e mais lucrativa possível”. O direito Humano à saúde decorre diretamente do direito à vida, sendo dever constitucional do Poder Público atuar para que seja respeitado, prevalecendo a dignidade humana. (TRETTEL, 2.010, p.47).

A relação entre operadoras de planos de saúde e consumidores ultrapassa, e muito, o alcance dos contratos e do vetusto princípio do pact sunt servanda, pois o resultado da prestação contratada é o bem mais valioso da vida, por ser a própria vida.

A saúde e a vida humana, de pessoas próximas, de relações consanguíneas, ascendentes, descendentes ou outras esferas afetivas, quando em risco, pode levar aquele que acompanha o sofrimento do enfermo a sofrimento semelhante causado pela condição de impotência e irresignação. Tanto assim é que o ordenamento jurídico pátrio proíbe expressamente, tornando nulo de pleno direito, e criminalizando a exigência de qualquer garantia como condição para atendimento médico-hospitalar emergencial quando necessário. ${ }^{2}$

Sobre a questão da criminalização de abusos praticados por hospitais no momento de atendimento aos usuários consumidores, Jussara Borges Ferreira e Kelly Cardoso Mendes de Moraes abordam o assunto de modo a não deixar dúvidas sobre a essência desta proteção mais que necessária:

\footnotetext{
${ }^{2}$ Disposição do Art. 135-A do Código Penal: Exigir cheque-caução, nota promissória ou qualquer garantia, bem como o preenchimento prévio de formulários administrativos, como condição para o atendimento médico-hospitalar emergencial:

Pena - detenção, de 3 (três) meses a 1 (um) ano, e multa.

Parágrafo único. A pena é aumentada até o dobro se da negativa de atendimento resulta lesão corporal de natureza grave, e até o triplo se resulta a morte."
} 
Porém, infelizmente, mesmo que exista previsão expressa, inclusive considerada como prática abusiva conforme o dispositivo no art. 39, inc. $\mathrm{V}$ do CDC, e nula de pleno direito, como o disposto no art. 51, I, IV, $\mathrm{XV}, \S 1^{\circ}, \mathrm{III}$, do $\mathrm{CDC}$, o desrespeito ao consumidor, e principalmente aos pacientes necessitados de atendimento emergencial, muitas vezes à beira da morte, é descabido e desumano, não condizente com o atual estado Democrático protetivo do direito à dignidade humana.

Não bastando a legislação já existente, na tentativa de coibir e punir criminalmente tal prática, foi publicada, em 28 de maio de 2012, a Lei n. 12.653 que acrescentou o art. 135-A ao Decreto-lei n. 2848, de 7 de dezembro de 1940 - Código Penal, tipificando como crime a exigência de cheque-caução, nota promissória ou qualquer garantia, bem como o preenchimento prévio de formulários administrativos como condição para o atendimento médico-hospitalar emergencial, com pena de detenção de 3 (três) meses a 1 (um) ano, e multa.(FERREIRA, MORAES, 2014, p.121)

É de se presumir que qualquer pessoa assumirá o mais desprestigioso compromisso em um momento de enfermidade, seu ou de pessoa próxima e de elevado afeto, restando ao legislador coibir e punir tal prática desumana que vinha ocorrendo desenfreadamente e que, conforme se observa acima, tal proteção já esta em vigor.

\section{NORMAS COGENTES DE ORDEM PÚBLICA}

As normas de eficácia cogente (ius cogens) disciplinam as relações entre entes ou pessoas privadas, mas com aplicabilidade de norma pública. Também podem ser Leis que regulam relações entre o Estado e as pessoas (físicas ou jurídicas) privadas. Este tipo de norma não permite flexibilização, quando da interpretação do contrato celebrado entre as partes.

Não se está buscando neste momento discutir sobre o alcance e a distinção entre direito público e direito privado, mas tão somente a definição de normas cogentes para a aplicação nos contratos de assistência à saúde.

A seguir, estudar-se-á a distinção entre norma de ordem pública e norma de ordem privada.

\subsection{NORMA DE ORDEM PÚBLICA}

As normas de ordem pública regulam as relações jurídicas relacionadas às atividades do Estado e de seus agregados e, ainda, as relações jurídicas entre os 
cidadãos e essas organizações políticas, cuidando, portanto, dos interesses diretos e ou indiretos do poder público. (FARIAS, ROSENVALD, 2015, p 12).

As normas de ordem pública restringem a interpretação dos contratos dentro dos limites que elas entabulam. As partes não podem alterar o sentido que a Lei estabelece.

Para Caio Mario, as normas de ordem pública não chegam a constituir o conhecido direito público, até pela falta de participação direta do Estado nas relações particulares. São consideradas as normas princípios de direito privado, tendo em vista sua natureza de tutela jurídica, sendo certo que atuam na tutela do coletivo. (PEREIRA, 2005, p.18).

Percebe-se que, para o autor, a norma de ordem pública difere de direito público. Um exemplo de aplicação nos contratos de assistência à saúde pode ser encontrado no Art. 10 e 12 da Lei 9.656/98 que assim dispõe:

\begin{abstract}
Art. 10: É instituído o plano referência de assistência à saúde, com cobertura assistencial médico-ambulatorial e hospitalar, compreendendo partos e tratamentos, realizados exclusivamente no Brasil, com padrão de enfermaria, centro de terapia intensiva, ou similar, quando necessária a internação hospitalar, das doenças listadas na Classificação Estatística Internacional de Doenças e Problemas Relacionados com a Saúde, da Organização Mundial de Saúde, respeitadas as exigências mínimas estabelecidas no art. 12 desta Lei, exceto:

$[\ldots]$
\end{abstract}

Observa-se, desta feita, que o Art. 10 estabelece exigências mínimas a serem respeitadas nos contratos de assistência à saúde.

Analisando o art. 10 com maior riqueza de detalhes, verifica-se ainda que ele cria exigências mínimas e estabelece exceções a serem respeitadas pelas partes, não sendo possível a estrapolação destes limites por vontade dos contratantes.

Portanto, as normas cogentes ou normas de ordem pública têm os efeitos de uma norma pública, mas sua natureza é de norma privada ou, como se verá a frente, norma privada supletiva.

\title{
3.2 NORMA DE ORDEM PRIVADA
}

As normas de ordem exclusivamente privada regulam necessariamente as relações entre entes privados, sejam pessoas físicas ou jurídicas. 
Invariavelmente as partes têm a opção de flexibilização da forma de contratação, não havendo normas restritivas, excetuando-se, é claro, a ilegalidade.

A norma de ordem privada (DINIZ, 2009, p.19) abrange o direito civil, que estabelece os direitos e obrigações de todas as pessoas alcançadas por aquele ordenamento jurídico.

Trata-se, portanto, de um direito mais amplo, que regula a maioria das atividades dos entes privados e que, em alguns casos, confunde-se com o direito público.

O direito privado regula as relações estabelecidas entre os particulares e entre estes e o Estado.

As relações estabelecidas dentro do manto das normas de direito privado podem ser flexíveis, adequando-se às vontades das partes (GONÇALVES, 2003, p.11). Mas, neste contexto de contratos de planos de saúde, prevalece a manifestação de vontade da operadora plasmada nos pactos de adesão, impedindo a possibilidade de manifestação de vontade por parte do aderente. Ainda que fosse invocada a tutela da confiança no sentido de justificar a opção do aderente por determinada operadora, permaneceria inafastável a prevalência da adesividade contratual, predominante neste ambiente negocial.

\subsection{A UNIFICAÇÃo DO DIREITO PRIVAdO E DIREITO PÚBLICO NO}

\section{BRASIL}

Um tema de grande recorrência entre os civilistas pátrios paira em torno da distinção entre direito privado e direito público no ordenamento jurídico brasileiro.

Há uma unanimidade sobre a questão de que o direito privado e o direito público entrelaçam-se, com diversos pontos de intersecção.

Para Cristiano Chaves de Farias e Nelson Rosenvald, "É nítida, pois, a superação da dicotomia direito público e privado, vislumbrando-se em alguns ramos da ciência jurídica pontos comuns, de contato, com um e outro ramo”. (FARIAS, ROSENVALD, 2015, p. 14.

A concepção mais adequada às normas de direito privado com eficácia de direito público, dentro do contexto ora abordado, que trata de relações entre entes 
privados, pode ser encontrada no conceito de Carlos R. Gonçalves, quando distingue norma privada em norma privada dispositiva e supletiva.

Neste sentido, Carlos Roberto Gonçalves esclarece as diferenças do seguinte modo:

Normas de ordem pública são as cogentes, de aplicação obrigatória. São as que se impõem de modo absoluto, não sendo possível a sua derrogação pela vontade das partes. Normas de ordem privada são as que vigoram enquanto a vontade dos interessados não convencionar de forma diversa, tendo, pois, caráter supletivo. Distinguem-se em dispositivas, "quando permitem que os sujeitos disponham como lhes aprouver", e supletivas "quando se aplicam na falta de regulamentação privada, preenchendo, no exercício de uma função integradora, as lacunas por ela deixadas".( GONÇALVES, 2003, p.11)

Portanto, descabe confundir direito público com normas de ordem privada supletivas, pois o direito público regula as relações entre Estados, ou entre Estados e seus cidadãos. Já as normas de ordem privada supletivas são normas que regulam as relações entre particulares, mas com a força de norma pública.

Sobre a interferência das normas de ordem pública nas relações privadas, Carlos Roberto Gonçalves destaca o quanto segue:

\begin{abstract}
Digno de nota o fenômeno, que vem se desenvolvendo atualmente, da acentuada interferência do direito público em relações jurídicas até agora disciplinadas no Código Civil, como as contratuais e as concernentes ao direito de propriedade, por exemplo. Tal interferência foi observada inicialmente na legislação especial (Estatuto da Criança e do Adolescente, Lei das Locações, Código de Defesa do Consumidor etc.) e, posteriormente, na própria Constituição Federal de 1998, a ponto de se afirmar hoje que a unidade do sistema deve ser buscada, deslocando para a tábua axiológica da Carta da República o ponto de referência antes localizado no Código Civil.( GONÇALVES, 2003, p.11)
\end{abstract}

E no sentido de intercalar eficácia de norma pública em norma privada, caracterizando justamente a interferência recíproca das normas, que o presente trabalho busca demonstrar que a interferência da força de norma pública alcança a Lei 9.656/98, que regula os contratos entre operadoras de planos de saúde e seus usurários, tornando-a norma de ordem privada supletiva.

\title{
4 RELAÇÃO DE CONSUMO NA LEI 9.656/98.
}


Segundo o art. 35-G da Lei 9.656/98, o Código de Defesa do Consumidor, que também é uma Lei de ordem pública, ou norma cogente, tem aplicação subsidiária sobre a Lei 9.656 de 1.998.

Observa-se, entretanto, que há o encontro de duas normas cogentes, no caso dos contratos de assistência à saúde. Por conta disso, a força cogente destes dispositivos se torna absoluta, pois não há margem para a interpretação diversa, senão a de que as regras e proteções ali dispostas devem ser seguidas protegendo o ente mais fraco da relação contratual.

A própria Lei 9.656 de 1.998 estabelece, no inciso I do art. $1^{\circ}$, que a relação por ela entabulada configura-se como uma relação de consumo.

Art. $1^{\circ}$ Submetem-se às disposições desta Lei as pessoas jurídicas de direito privado que operam planos de assistência à saúde, sem prejuízo do cumprimento da legislação específica que rege a sua atividade, adotando-se, para fins de aplicação das normas aqui estabelecidas, as seguintes definições:

I - Plano Privado de Assistência à Saúde: prestação continuada de serviços ou cobertura de custos assistências a preço pré ou pós estabelecido, por prazo indeterminado, com finalidade de garantir, sem limite financeiro, a assistência à saúde, pela faculdade de acesso e atendimento por profissionais ou serviços de saúde, livremente escolhidos, integrantes ou não da rede credenciada, contratada ou referenciada, visando a assistência médica, hospitalar e odontológica, a ser paga integral ou parcialmente às expensas da operadora contratada, mediante reembolso ou pagamento direto ao prestador, por conta e ordem do consumidor.(grifo nosso) ${ }^{3}$

A lei regulamentadora que trata dos contratos de assistência privada à saúde, em seu artigo definidor do objeto do contrato, estabelece que o contratante é um consumidor.

A respeito do Código de Defesa do Consumidor ser ou não norma de ordem pública, o professor Nelson Nery (NERY JR, 1992, p.51-52) não deixa dúvidas quando, ao analisar o art. $1^{\circ}$ da Lei 8.078/90, assevera que:

As normas do CDC são de ordem pública e interesse social. Isto quer dizer, do ponto de vista prático, que o juiz deve apreciar ex officio qualquer questão relativa às relações de consumo, já que não incide nesta matéria o princípio dispositivo. Sobre elas não se opera a preclusão e as questões que delas surgem podem ser decididas e

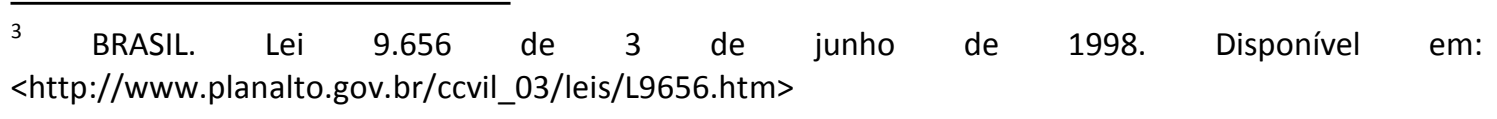


revistas a qualquer tempo e grau de jurisdição. $O$ Tribunal pode, inclusive, decidir conta o único recorrente, reformando a decisão recorrida para pior, ocorrendo assim o que denominamos de reformatio in pejus permitida, já que se trata de matéria de ordem pública a cujo respeito a lei não exige a iniciativa da parte, mas o contrário, determina que o juiz a examine de ofício. Ser de interesse social significa, em termos práticos, que o Ministério Público tem participação obrigatória em todas as ações sobre lides do consumidor (...).

Não há o que se contra-argumentar quando a questão for sobre a aplicabilidade do Código de Defesa do Consumidor como norma de eficácia cogente, pois este ponto já está amplamente pacificado no ordenamento jurídico pátrio.

Cumpre destacar, conforme já asseverado inicialmente, que o art. 35-G da Lei 9.656/98 dispõe que "Aplicam-se subsidiariamente aos contratos entre usuários e operadoras de produtos de que tratam o inciso $I$ e o $\$ 1^{\circ}$ do art. $1^{o}$ desta lei as disposições da Lei 9.078/90."

Tal dispositivo pode causar confusão ao interpretar a norma à luz do Código de Defesa do Consumidor, pois, do modo como está expresso, admitir-se-ia que o Código consumerista estaria em desvantagem em relação à Lei 9.656/98, tendo sua aplicação subsidiária.

Este entendimento cai por terra ao analisar a afirmativa de Claudia Lima Marques quando trata de contrato de assistência à saúde:

Destaque-se, também, que o contrato de planos de saúde, como hoje é regulado pela Lei de 1998 e pelo CDC de 1990, apresenta muitas semelhanças com o contrato clássico de fornecimento de serviços médico-hospitalares simples, isto é, aquele fechado por um consumidor que procura o médico ou hospital na atualidade de sua doença ou acidente e não em face de um seguro ou previsão de eventual doença futura. (grifo nosso) (MARQUES, 2014, p. 535)

Faz-se necessário deixar notório que a doutrinadora afirma textualmente que o contrato de plano de saúde é regulado pela Lei 9.656/98 e 8.078/90, não apontando o Código de Defesa do Consumidor como legislação suplementar.

Seguindo este entendimento, o Colendo Superior Tribunal de Justiça - STJ editou, em novembro de 2010, a súmula 469 em que apresenta "o entendimento daquela Corte sobre aplicabilidade do Código de Defesa do Consumidor na Lei 9.656, nos seguintes termos: Aplica-se o Código de Defesa do Consumidor aos contratos de planos de saúde." 
Portanto, dúvidas não restam de que a relação entabulada entre as partes forma uma relação de consumo, com aplicabilidade cogente, tanto da Lei 9.656/98 quanto da Lei 8.078/90.

As forças cogentes das duas normas devem ser aplicadas ex officio pelo magistrado, observando-se, sobretudo, o estado de hipossuficiência em que se encontra o contratante e seus familiares, no momento da prestação dos serviços elencados na Lei 9.656/98.

O Código de Defesa do Consumidor é perfeitamente admissível de forma cumulativa e complementar à Lei 9.656/98 (GREGORI, 2010, p.168), sendo que do primeiro se observam os princípios aplicáveis ao consumidor e, ao segundo, as regras a serem aplicadas nos contratos de assistência à saúde.

\subsection{INTERPRETAÇÃO MAIS BENÉFICA AO CONSUMIDOR}

Sendo a Lei 9.656 de 1.998, norma cogente e, ainda, complementada pelo Código de Defesa do Consumidor, a melhor interpretação desta Lei não pode se furtar a alguns pontos específicos.

O artigo 42 da Lei 8.078/90 estabelece que "As cláusulas contratuais serão interpretadas de maneira mais favorável ao consumidor" não restando dúvidas de que a norma cogente ao ser interpretada deverá proteger a parte contratante hipossuficiente, ou seja, o consumidor.

Não poderá haver alegação de que determinado artigo da Lei 9.656/98 não fere a da Lei 8.078/90, quando a interpretação daquela em conjunto desta desprivilegia o consumidor.

Deste modo, as determinações trazidas pelos arts. $1^{\circ}, 7^{\circ}$ e 47 da lei 8.078/901 impõem uma hermenêutica especial aplicada aos contratos de consumo, podendo ser denominadas (MARQUES, 2.014, p. 952) “hermenêutica mais favorável ao consumidor".

A doutrina e a jurisprudência são unânimes em tal determinação, afinal, existe uma tendência mundial na constitucionalização dos direitos dos contratos (MARQUES, 2.014, p. 952), conforme já decidiu o Superior Tribunal de Justiça.

em que há nítida possibilidade de violação ao direito fundamental à vida, 'se o juiz não reconhece, no caso concreto, a influência dos 
direitos fundamentais sobre as relações privadas, então ele não apenas lesa o direito constitucional objetivo, como também afronta direito fundamental considerado como pretensão em face do estado, ao qual, enquanto órgão estatal, está obrigado a observar' (RE 201.819, rel. Min. Ellen Gracie, rel. p/ Acórdão: Min. Gilmar Mendes, $2^{\mathrm{a}}$ T., j. 11.10.2005 DJ 27.10.2006" (REsp 962.980/SP, rel. Min. Luis Felipe Salomão, $4^{\mathrm{a}}$ T., j. 13.03.2012, DJe 15.05.20102).

Sobre a hermenêutica mais favorável ao consumidor, destaca-se a lição de Lenio Streck ao reafirmar a perspectiva hermenêutica prática que deve ser aplicada aos contratos de assistência à saúde submetidos ao CDC.

Por outro lado, há também uma perspectiva (prática) na medida em que essa derivação visa a atingir um resultado: procura estabelecer regras e métodos que conformem de tal modo o processo de interpretação e compreensão que torne possível reduzir os erros e malentendidos que possam surgir da leitura dos textos. Assim, a hermenêutica não pretende apenas reunir um conjunto de conhecimentos teóricos acerca do problema interpretativocompreensivo, mas, na trilha do iluminismo-racionalista, pretende também produzir critérios para a afirmação de certeza e objetividade no processo de interpretação e compreensão. (STRECK, 2014, p. 262)

Deste modo, por onde quer que se analise a questão de interpretação das normas de modo mais favorável ao consumidor, principalmente nos casos de contratos de assistência à saúde do consumidor, que tem como objeto final da prestação de serviços de manutenção da saúde e da vida, as normas devem ser interpretadas aplicando-se o Código de Defesa do Consumidor e ainda, interpretando-se os casos concretos de maneira mais favorável a estes.

\subsection{BOA FÉ OBJETIVA NOS CONTRATOS DE ASSITÊNCIA A SAÚDE}

O princípio da boa-fé objetiva, consagrado pelo Código Civil de 2002, Art. 422, definiu a conduta moral dos contratantes, impondo dever a ser observado durante a execução e conclusão dos contratos.

Os valores que direcionam a boa-fé são a probidade, a lealdade e a consideração às mais legítimas expectativas do outro contratante. (MARTINS-COSTA, p. 195, 2014).

No que se refere às relações obrigacionais de consumo, observa-se a interligação entre o princípio da boa-fé, o postulado fático-normativo da vulnerabilidade 
do consumidor (a desigualdade entre as partes é legalmente presumida), o dever jurídico da transparência embasando o equilíbrio nas relações de consumo.

A boa fé objetiva diz respeito ao comportamento do agente em determinada relação jurídica, consistindo em um padrão de conduta, que pode variar as exigências de acordo com o tipo de relação estabelecida entre as partes.

O professor Álvaro Villaça Azevedo, conclui que a boa-fé objetiva constitui um estado de espírito, sendo essência do entendimento entre os seres humanos e a presença da ética na celebração dos contratos, trazendo segurança jurídica aos contratantes, principalmente quando assevera:

O princípio da boa-fé deve ser, antes de tudo, mencionado, pois ele assegura o acolhimento do que é lícito e a repulsa ao ilícito.

A contratação de boa-fé é a essência do próprio entendimento entre os seres humanos, é a presença da ética nos contratos.

Sim, porque a aplicação do princípio da boa-fé é um estado de espírito que leva o sujeito a praticar um negócio em clima de aparente segurança.

Daí porque todos os Códigos e todos os sistemas jurídicos são escudados no princípio da boa-fé, que supera, até, o princípio da nulidade dos atos jurídicos, pois os atos nulos, em certos casos, produzem efeitos, e até os atos inexistentes, para premiar a atuação de boa-fé, como é o caso da validade do pagamento do credor putativo, da transmissão da herança ao herdeiro aparente, dos efeitos em favor do cônjuge de boa-fé no casamento putativo. (ALVIM, CERQUEIRA CESAR, ROSAS, 2003 p.34)

A este respeito, Pablo Stolze e Rodolfo Pamplona Filho, não deixam dúvidas que a boa-fé objetiva é regra imprescindível a ser observada pela sociedade hodierna, quando pontua:

A resposta a essas últimas indagações, portanto, encontra-se na definição da boa-fé objetiva, que, conforme já vimos, consiste em uma imprescindível regra de comportamento, umbilicalmente ligada à eticidade que se espera seja observada em nossa ordem social. (GAGLIANO, PAMPLONA FILHO, 2006, p.66)

Verifica-se, nesse sentido, que a boa-fé objetiva busca proteger a parte mais fraca na relação contratual, principalmente no que concerne à relação de consumo, trazendo equilíbrio entre as partes.

Seguindo esta esteira, inegável a importância da invocação da função social do contrato, relevante ao estudo e abordada a seguir. 


\subsection{A FUNÇÃO SOCIAL DO CONTRATO NAS RELAÇÕES DE CONSUMO APLICADAS NOS CONTRATOS DE ASSISTÊNCIA A SAÚDE PRIVADA}

Em boa parte das relações de consumo, celebram-se pactos por meio de contratos informais, consoante a prática do mercado e passando desde simples compra de objetos de pequena expressão até a compra de bem móveis de alta monta.

De outra parte, o grande plexo de contratos formais são revestidos dos requisitos legais à modalidade a que se destina, como quando o consumidor adere a um plano de saúde, contratando com empresa que presta os serviços descritos no inciso I do art. $1^{\circ}$ da Lei 9.656/98.

Por sua vez, a Lei 10.406/2002 trouxe inúmeras inovações ao ordenamento jurídico brasileiro no que diz respeito à celebração de contratos, sobretudo, na questão de sua função social.

Prescreve o art. 421 do Código Civil que: A liberdade de contatar será exercida em razão e nos limites da função social do contrato.

O princípio da função social avulta em importância por implicar mais um dos movimentos metodológicos referentes à funcionalização, rompendo com $\mathrm{o}$ individualismo e orientado para a tutela coletiva dos interesses.

Para Teresa Negreiros, o princípio da função social do contrato "condiciona o exercício da liberdade contratual e torna o contrato como situação jurídica merecedora de tutela erga omnes. Isto é, todos têm o dever se abster da prática de atos que saibam prejudiciais ou comprometedores da satisfação de créditos alheios”. (NEGREIROS, 2002,p.264).

O princípio da função social do contrato contribuiu fortemente em relação ao controle da abusividade de cláusulas, prática recorrente no universo dos pactos por adesão, envolvendo interesses, via de regra, patrimoniais, contrários aos interesses sociais.

\footnotetext{
A função social do contrato, portanto, na acepção mais moderna, desafia a concepção clássica de que os contratantes tudo podem fazer, porque estão no exercício da autonomia da vontade. O reconhecimento da inserção do contrato no meio social e da sua função como instrumento de enorme influência na vida das pessoas, possibilita um maior controle da atividade das partes. Em nome do princípio da função social do contrato se pode, v.g., evitar a inserção de cláusulas que venham injustificadamente a prejudicar terceiros ou mesmo proibir a contratação tendo por objeto determinado bem, em razão do interesse maior da coletividade. (PEREIRA, 2007, p.14)
} 
Acompanhando este magistério, são destacados avanço na interpretação contratual, resultado de um corolário hermenêutico, permitindo contratações amparadas pelo equilíbrio e segurança jurídica que há tempos era clamada pelos contratantes.

Corroborando o entendimento de segurança jurídica e equilíbrio contratual, Carlos Roberto Gonçalves leciona que:

É possível afirmar que o atendimento a função social do contrato pode ser enfocado sob dois aspectos: um, individual, relativo aos contratantes, que se valem do contrato para satisfazer seus interesses próprios, e outro, público, que é o interesse da coletividade sobre o contrato. Nessa medida, a função social do contrato somente estará cumprida quando a sua finalidade - distribuição de riquezas - for atingida de forma justa, ou seja, quando o contrato representar uma fonte de equilíbrio social.(GONÇALVES, 2010, p.26 )

Dúvidas não restam de que, sobretudo, nas contratações que envolvem assistência à saúde, a função social do contrato deve ser observada e respeitada pelas operadoras de planos de saúde, pois, em regra, os referidos contratos são na modalidade adesão, não se permitindo a discussão de cláusulas ou reivindicações por parte dos consumidores contratantes.

Este tipo de contratação é um dos melhores exemplos de onde a aplicação da função social dos contratos deve ser referenciada e aplicada, como vêm fazendo os Tribunais pátrios.

\section{DADOS DA AGÊNCIA NACIONAL DE SAÚDE SUPLEMENTAR - ANS- SOBRE USUÁRIOS DE CONTRATOS DE ASSISTÊNCIA}

Os contratos de assistência à saúde, conforme se verificará no demonstrativo ${ }^{4} \mathrm{a}$ seguir, exprimem a esmagadora quantidade de usuários/consumidores vinculados aos contratos coletivos, seja por adesão ou empresarial.

Somando-se as duas modalidades de contratos coletivos, alcança-se o número de 39.748.923 (trinta e quatro milhões, setecentos e quarenta e oito mil e novecentos e vinte e três) vidas, contra 9.627.134 (nove milhões, seiscentos e setenta e dois mil e cento e trinta e quatro) vidas na modalidade individual e familiar.

\footnotetext{
4 Informação extraída do sitio da Agência Nacional de Saúde Suplementar disponível em: <http://www.ans.gov.br/perfil-do-setor/dados-gerais> acessado da data de 15/03/2016.
} 
Estes dados revelam informações cruciais para a efetiva interpretação da análise e defesa do consumidor, devendo ser questionada em qual situação está o maior número de usuários/consumidores contratantes de assistência médica privada.

\begin{tabular}{|l|l|l|l|}
\hline Cobertura assistencial e tipo de contratação do plano & Total & Novo & Antigo \\
\hline Assistência médica com ou sem odontologia & $\mathbf{4 9 . 7 3 0 . 4 0 5}$ & $\mathbf{4 4 . 3 9 5 . 1 0 5}$ & $\mathbf{5 . 3 3 5 . 3 0 0}$ \\
\hline Individual ou Familiar & 9.672 .134 & 8.433 .160 & 1.238 .974 \\
\hline Coletivo Empresarial & 33.123 .445 & 30.842 .700 & 2.280 .745 \\
\hline Coletivo por adesão & 6.625 .478 & 5.109 .081 & 1.516 .397 \\
\hline Coletivo não identificado & 9.153 & 9.153 & 0 \\
\hline Não Informado & 300.195 & 1.011 & 299.184 \\
\hline & & & \\
\hline Exclusivamente odontológicos & & & \\
\hline Individual ou Familiar & $\mathbf{2 1 . 9 5 0 . 4 6 3}$ & $\mathbf{2 1 . 5 1 8 . 7 5 8}$ & $\mathbf{4 3 1 . 7 0 5}$ \\
\hline Coletivo Empresarial & 3.889 .264 & 3.880 .744 & 8.520 \\
\hline Coletivo por adesão & 16.074 .121 & 15.773 .298 & 300.823 \\
\hline Coletivo não identificado & 1.917 .002 & 1.860 .134 & 56.868 \\
\hline Não Informado & 4.334 & 4.334 & 0 \\
\hline
\end{tabular}

Fonte: Sistema de Informações de Beneficiários/ANS/MS - 12/2015

Tribunais pátrios ${ }^{5}$, ao julgarem ações que envolvem contratos coletivos, sejam empresariais ou por adesão, restringem a hipossuficiência dos consumidores alegando as mais variadas justificativas.

5 Ementa: APELAÇÃO CÍVEL. PRELIMINAR DE NULIDADE DA SENTENÇA. INOCORRÊNCIA. PLANO DE SAÚDE. AÇÃO DECLARATÓRIA CUMULADA COM REPETIÇÃO DE INDÉBITO. REAJUSTE ANUAL DO PRÊMIO. CONTRATO COLETIVO. 1. Determinação de juntada de documento. Desnecessidade. A documentação requerida não se apresenta indispensável para o deslinde da presente controvérsia, pois se trata de matéria exclusivamente de direito, sendo que os fatos alegados podem e devem ser demonstrados através da juntada de documentos, de incumbência das partes, e da análise das provas coligidas ao caderno processual. Preliminar desacolhida. 2. Não se mostra abusivo o reajuste anual dos planos de saúde coletivo em percentual superior ao fixado pela ANS aos planos de saúde individual ou familiar, pois a agência reguladora não define teto para os planos coletivos. Em se tratando de contrato coletivo, o reajuste deve ser comunicado à ANS. Resolução Normativa 156/2007 da Diretoria Colegiada da ANS e Instrução Normativa 13/2006 da Diretoria de Normas e Habilitação dos Produtos da ANS. 3. Prequestionamento. O Julgador não está obrigado a enfrentar todos os dispositivos legais suscitados no processo. PRELIMINAR DESACOLHIDA E APELAÇÃO DESPROVIDA. (Apelação Cível No 70067640177, Quinta Câmara Cível, Tribunal de Justiça do RS, Relator: Isabel Dias Almeida, Julgado em $16 / 12 / 2015)$ 
A título de exemplo clássico desta desvirtuação da interpretação da Lei Consumerista, bem como da Lei 9.656/98 ambas de aplicação cogente, analisar-se-á o art. 13 da Lei 9.656/98 que assim dispõe:

Art. 13. Os contratos de produtos que tratam o inciso I e o $\S 1^{\circ}$ do art. $1^{\circ}$ desta Lei têm renovação automática a partir do vencimento do prazo inicial de vigência, não cabendo a cobrança de taxas ou qualquer outro valor no ato da renovação. (redação dada pela Medida Provisória nº 2.177-44, de 2001)

Parágrafo único: Os produtos de que trata o caput, contratados individualmente, terão vigência mínima de um ano, sendo vedadas:

I - (omissis)

II - a suspensão ou a rescisão unilateral do contrato, salvo por fraude ou não pagamento da mensalidade por período superior a sessenta dias, consecutivos ou não, nos últimos doze meses de vigência do contrato, desde que o consumidor seja comprovadamente notificado até o quinquagésimo dia de inadimplência; e

$[\ldots]$

O exercício hermenêutico deste artigo autoriza a afirmação de que não poderá haver rescisão unilateral do contrato, no caso da contratação individual ou familiar sem as referidas causas elencadas no texto do inciso II.

Entretanto, a grande maioria dos contratantes/consumidores deverá ficar de fora da segurança estabelecida pelo art. 13 da Lei 9.656/98.

Esses usuários, por ventura, não são seres humanos, ou sequer consumidores, para não serem protegidos pela Lei que teve como natureza jurídica a proteção da sociedade?

Estes questionamentos se fazem necessários, pois da forma que se encontram alguns entendimentos, conforme já demonstrado, a rescisão unilateral de forma injustificada por parte das operadoras somente é vedada pela Lei nos casos de contratos individuais.

A hermenêutica utilizada para alcançar este raciocínio perdeu-se no caminho do seu fim, pois se torna totalmente ilógico deixar a grande massa de usuários/consumidores desprotegida nos casos de rescisão unilateral por parte das operadoras. Este entendimento deve ser revisto e adequado a melhor hermenêutica a ser 
aplicada aos casos de contratos privados de assistência à saúde, a fim de que a grande população contratante destes produtos esteja efetivamente protegida, tanto pela Lei consumerista, quanto pela Lei de Planos de Saúde.

\section{CONCLUSÃO}

$\mathrm{O}$ direito à saúde e a defesa do consumidor como direito fundamentais, protegidos constitucionalmente, têm de ser acolhidos e respeitados sob pena de violação superlativa da Carta Magna.

A Constituição de 1.988 quando permitiu que a assistência à saúde fosse prestada pela iniciativa privada, encarregou-a da tutela e cumprimento de seus mais essenciais princípios.

Adveio, posteriormente, em 1.990, o Código de Defesa do Consumidor, carregando ainda mais as responsabilidades da iniciativa privada na contratação com consumidores, que passaram a ser reconhecidos como hipossuficientes, carecendo de proteção e respeito.

Em 1.998 foi publicada a Lei 9.656 que passou a regular os contratos de assistência à saúde e, por meio da Lei 9.961/2000, criou-se a Agência Nacional de Saúde Suplementar - ANS que passou a fiscalizar e, em tese, deveria proteger os consumidores.

Seguindo a cronologia do tempo, em 2002 entrou em vigor o novo Código Civil, trazendo avanços importantíssimos no que diz respeito à função social dos contratos e a boa-fé no direito privado, que inserido no contexto dos contratos de assistência à saúde trouxe segurança jurídica aos contratantes mais fracos.

As aplicações das normas descritas como cogentes ou normas de direito privado supletivas, principalmente a Lei $9.656 / 98$ e a Lei $8.078 / 90$, de modo mais benéfico ao consumidor, deve ser prática costumeira dos juízes de primeira instância, bem como dos Tribunais Superiores, a fim de se estabelecer a mais eficaz segurança jurídica e equilíbrio contratual, como pretendido pelos consumidores, contratantes deste contexto negocial.

As empresas que pretenderem adentrar e operar estes referidos contratos devem ter por meta que o resultado final da prestação de seus serviços será a manutenção da saúde e das vidas das pessoas sendo, portanto, o bem da vida - a própria vida em si-, 
características consubstanciadas pelo risco do negócio, e que deve ser considerado no momento de analisar a viabilidade de ingresso neste meio.

A responsabilidade por tal prestação de serviços se torna, dentro deste contexto, uma das mais importantes prestações a serem realizadas em uma sociedade. Esta responsabilidade vem carregada da necessidade de observação da boa-fé objetiva e da função social do contrato, sob pena de responderem não só pelo eventual descumprimento do contrato, mas, sobretudo, pela saúde e vida das pessoas.

Os tribunais pátrios devem permanecer na construção do caminho hermenêutico da melhor interpretação aos casos concretos quanto se tratar de contratação de serviços de saúde, pois, além de serem hipossuficientes técnica e economicamente, os consumidores e seus familiares estão, em geral, fragilizados seja pela doença, acidente ou qualquer outro motivo que ocasionou a prestação de serviços médicos.

\section{REFERÊNCIAS}

ALVIM, Arruda, CÉSAR, Joaquim Portes de Cerqueira, ROSAS, Roberto (coordenação), Aspectos controvertidos do novo código civil: escritos em homenagem ao Ministro José Carlos Moreira Alves. São Paulo: Editora Revista dos Tribunais, 2003.

DINIZ, Maria Helena. Curso de direito civil brasileiro, vol. 1: teoria geral do direito civil. 26. ed. Reformulada. São Paulo: Saraiva, 2009.

GAGLIANO, Pablo Stolze, PAMPLONA FILHO, Rodolfo. Novo curso de direito civil, volume IV: contratos, tomo 1: teoria geral. 2. ed. ver., atual. e reform. São Paulo: Saraiva, 2006.

GONÇALVES, Carlos Roberto. Direito civil brasileiro, vol. 1: Parte geral. São Paulo: Saraiva, 2003.

GONÇALVES, Carlos Roberto. Direito civil brasileiro: Contratos e atos unilaterais. 7.ed. São Paulo: Saraiva, 2010.

FARIAS, Cristiano Chaves de. ROSENVALD, Nelson. Curso de direito civil: parte geral e LINDB, volume 1. 13. Ed. rev., ampl. E atual. São Paulo: Atlas, 2015.

FERREIRA, Jussara Borges. MORAES, Kelly Cardoso Mendes de. Contratos bancários e de planos de saúde: a aplicabilidade do incidente de demandas repetitivas. Belo Horizonte: Arraes Editores, 2014.

MARQUES, Claudia Lima. Contratos no código de defesa do consumidor: O novo regime das relações contratuais. 7. ed. rev. atual. e ampl. São Paulo: Revista dos Tribunais. 2.014. 
MARTINS-COSTA, Judith. FRADERA, Véra Jacob de, organizadoras. Estudos de direito privado e processual civil: em homenagem a Clóvis do Couto e Silva. São Paulo: Editora Revista dos Tribunais, 2014.

NEGREIROS. Teresa, Teoria do contrato: novos paradigmas. Rio de Janeiro:Renovar, 2002.

NERY JUNIOR, Nelson. Os Princípios gerais do Código de Defesa do Consumidor. Revista de Direito do Consumidor, n3, São Paulo, RT, set-dez. 1992.

PEREIRA, Caio Mario da Silva. Instituições de direito civil. Vol. I. Introdução ao direito civil. Teoria geral de direito civil. Rio de janeiro: 21. ed. Forense,2005.

PEREIRA, Caio Mario da Silva. Instituições de direito civil. Vol. III. Contratos. 12. ed. rev. atual. Rio de Janeiro, 2007.

STRECK, Lenio Luiz. Hermenêutica jurídica e $(\mathrm{m})$ crise: Uma exploração hermenêutica da construção do direito. 11. ed. Ver., atual. e ampl. Porto Alegre: Livraria do Advogado Editora, 2014.

TRETTEL, Daniela Batalha. Planos de saúde na visão do STJ e do STF. São Paulo: Ed. Verbatim, 2010. 